\title{
La Alcalinidad Y La Nitrificación En Una Laguna Aireada A Escala Piloto
}

\author{
Ing. Agustín Leiva Pérez, Ph.D. \\ Ing. Edison Macías Andrade, M.Sc. \\ Ing. Joffre A. Andrade Candell, M.Sc. \\ Q.F. Ana M. Aveiga Ortiz, Ing. \\ Sergio S. Alcívar Pinargote, M.Sc
}

Docentes - Investigadores de la Escuela Superior Politécnica Agropecuaria de Manabí - MFL

doi: 10.19044/esj.2016.v12n36p89 URL:http://dx.doi.org/10.19044/esj.2016.v12n36p89

\begin{abstract}
It was evaluated the relationship between organic nitrogen concentration and the nitrifying efficiency in a Conventional Activated Sludge System, employing, as inoculum, the Trickling Filter microorganisms. The independent variable was the aerobic reactor operation time, varying from zero up to 50 days. The initial total concentration was adjusted to $70 \mathrm{mg} / \mathrm{dm} 3$, by means of lysine addition and, the dissolved oxygen concentration stayed at least in $3 \mathrm{mg} / \mathrm{dm} 3$. The maximum nitrification efficiency was $86 \%$ about 30th day. The alkalinity (expressed as $\mathrm{CaCO} 3$ ) significantly decreased from 425 to $57 \mathrm{mg} / \mathrm{dm} 3$, in a similar way as the nitrification efficiency increased. The study will carry on employing a continuous activated sludge system taking into consideration these results.
\end{abstract}

Keywords: Nitrifying, alkalinity, dissolved oxygen, lysine, activated sludge system, trickling filter.

\section{Resumen}

Se estudió el comportamiento de la relación entre concentración de la alcalinidad del medio, medida como carbonato de calcio, y el proceso de nitrificación en una laguna de oxidación aireada en batch a escala piloto $(1,72$ $\mathrm{m}^{3}$ de volumen total y $1,46 \mathrm{~m}^{3}$ de volumen efectivo), partiendo de un residual líquido sintético, elaborado con base en sacarosa, sulfato y fosfato de amonio. Los resultados demostraron que al incrementarse la alcalinidad inicial en el rango de 120 a $360 \mathrm{mg} \mathrm{CaCO} / / \mathrm{dm}^{3}$, la eficiencia del proceso de nitrificación aumentó significativamente hasta los alrededores del 86\%, reduciéndose al estar esta con valores menores y mayores que dicho rango. La concentración 
de oxígeno disuelto se mantuvo por sobre los $4,3 \mathrm{mg} / \mathrm{dm}^{3}$, correspondiéndose con el carácter aerobio de las bacterias nitrificantes (géneros Nitrosomona y Nitrobacter). La concentración inicial de nitrógeno total en cada uno de los 14 procesos batch fue de $38 \mathrm{mg} / \mathrm{dm}^{3}$ y la misma bajó a mínimos de alrededor de $4,56 \mathrm{mg} / \mathrm{dm}^{3}$.

Palabras clave: Nitrificación, alcalinidad, oxígeno disuelto, lisina, sistema de lodos activados, lecho bacteriano aerobio.

\section{Introducción}

Las lagunas de oxidación aireadas son dispositivos que, mediante la introducción de oxigeno por alguna vía mecánica, proveen la bioxidación de la materia orgánica contenida en las aguas residuales de diferentes fuentes, entre ellas se distinguen las residuos líquidos domésticos, que contienen suficiente carbono, nitrógeno y fósforo, como sustrato de bacterias aerobias que oxidan tanto al carbono como al nitrógeno (nitrificación), transformándolo en nitratos $\left(\mathrm{NO}_{3}{ }^{-}\right)$y nitritos $\left(\mathrm{NO}_{2}{ }^{-}\right)$, a expensas del oxígeno disuelto del medio acuoso.

En la práctica se repiten casos en que las eficiencias de eliminación de materia orgánica son satisfactorias, sin embargo los efluentes de los procesos no están suficientemente nitrificados, provocando crecimiento excesivo de materia vegetal, deteriorando la calidad de las mismas, en relacionada con la apariencia y sus posibles o potenciales usos.

La investigación que se reporta persiguió el objetivo de estudiar la influencia de la alcalinidad del medio en la eficiencia de nitrificación en el mismo, considerando la bioxidación de la materia orgánica que se produce en una laguna aireada a escala piloto.

Se han realizado algunos trabajos a escala de laboratorio sobre nitrificación, por ejemplo, Carrera (s/f) comprobó que el proceso de nitrificación puede ser negativamente afectado por el amonio, el nitrito y el fluoruro. Según Jarpa et al. (2007), determinaron de la capacidad nitrificante de un sedimento marino proveniente de un centro de cultivo de salmones y sus resultados muestran la baja actividad nitrificante presente en los sedimentos, obteniéndose para bacterias amonio oxidantes producciones de 197 - 206 $\mathrm{mg} \cdot / \mathrm{dm}^{3} \mathrm{~N}-\mathrm{NO}_{2}{ }^{-}$, velocidades de consumo de $\mathrm{O}_{2}$ con respecto del factor estequiométrico de $0,023 \mathrm{mg} / \mathrm{dm}^{3} \cdot \min \mathrm{N}$ y consumo neto de $\mathrm{O}_{2}$ de 0,055 $\mathrm{mg} / \mathrm{dm}^{3} \cdot \mathrm{min}$; asimismo, concluyeron la incapacidad de las bacterias nitrificantes de oxidar la gran cantidad de compuestos nitrogenados generados por esta actividad acuícola. APHA, AWWA, WPCF (2000), plantean que las manifestaciones del nitrógeno de mayor interés en las mismas son el amoniacal y el total. 
El amonio $\left(\mathrm{NH}_{4}{ }^{+}\right)$es uno de los componentes de relativa permanencia en el agua, como integrante del ciclo del nitrógeno y sus concentraciones dependen de la actividad biológica. Es un producto natural de la descomposición de los compuestos orgánicos nitrogenados. Las aguas superficiales no deben contener normalmente amoniaco. En general, la presencia de amoniaco libre o ion amonio se considera como una prueba química de contaminación reciente y peligrosa. Si el medio es aerobio, el nitrógeno amoniacal se transforma en nitritos y ulteriormente en nitratos.

Leiva et al. (2016) resumen que el nitrógeno presente en el medio acuático puede existir en cuatro formas diferentes: nitrógeno orgánico, nitrógeno amoniacal, compuesto en forma de nitritos y compuestos en forma de nitratos. En un agua residual sin tratar están presentes las dos primeras. La descomposición por las bacterias transforma fácilmente el nitrógeno orgánico en amoniacal en la cantidad relativa de amoníaco presente es un indicativo de la edad del agua residual.

El sistema de laguna aireada está constituido por un estanque sobre el terreno o excavado en este, generalmente de flujo continuo, en el que el medio mantiene oxígeno disuelto mediante aireación mecánica, por ejemplo, el método más usado es el de los aireadores superficiales, que accionados por un rotos eléctrico, sus aspas al girar elevan al aire al medio acuoso, ocurriendo la transferencia del oxígeno del aire al medio acuoso. Pueden ser más profundas (entre 2 y 4,5 m) que las llamadas lagunas de oxidación aerobias. Muchas de ellas están revestidas con una membrana plástica protectora para minimizar la posibilidad de infiltraciones y reducir el efecto de la turbulencia provocada por los aireadores sobre los terraplenes y el fondo de la laguna (Guía Ambiental, 2010). Los aireadores deben ser dispuestos de manera tal que el radio de acción ocupe la mayor superficie posible.

Según Metcalf y Eddy Inc. (2005) y Tchobanoglous y Crites (2000), el diseño del tanque de aireación de un Sistema de Lodos Activados, se basa en la cinética química de primer orden para la oxidación de la materia orgánica carbonácea, que es la que se tiene en cuenta para su dimensionamiento, principalmente a los factores, Tiempo medio de retención celular $(5-15 \mathrm{~d})$, concentración de sólidos suspendidos volátiles del licor mezclado $(1,5-3$ $\mathrm{kg} / \mathrm{m}^{3}$ ), coeficiente de rendimiento microbiano en el aprovechamiento del sustrato $(0,4-0,8 \mathrm{mg} / \mathrm{mg})$, la Demanda Bioquímica de Oxígeno de 5 días del afluente $\left(0,2-1,8 \mathrm{~kg} / \mathrm{m}^{3}\right)$ y del efluente $\left(\mathrm{kg} / \mathrm{m}^{3}\right)$ y, la constante de muerte $\left(0,04-0,075 \mathrm{~d}^{-1}\right)$.

Generalmente a continuación del estanque aireado se coloca un sedimentador secundario para la eliminación de la biomasa (bacterias en su mayoría) producida en el proceso de eliminación de la materia orgánica. 


\section{Desarrollo}

\section{Materiales y Métodos}

Para la constitución del Sistema de laguna aireada se utilizó un tanque de fibra de vidrio, de características similares a las de un hidromasaje mecánico, de $1,72 \mathrm{~m}^{3}$ de volumen total y $1,46 \mathrm{~m}^{3}$ de volumen efectivo, que emplea una motobomba propulsora y mezcladora de líquido - aire, de $1 \mathrm{hp}$, $60 \mathrm{hz}, 3450 \mathrm{rpm}, 115$ volt y 10,5 amp. Asimismo, se empleó un analizador de oxígeno disuelto del tipo PCE - PHD 1, con medidor de temperatura.

Se procedió a la puesta en marcha de cada uno de 14 procesos batch, previa adición del agua residual sintética, cuya concentración inicial de nitrógeno total fue de alrededor de $38 \mathrm{mg} / \mathrm{dm}^{3}$ (medido empleando los métodos estándar, APHA, 2000). El reactor se activó con lodo secundario del sedimentador de un sistema de lecho bacteriano aerobio, el cual se inoculó al inicio de cada una de las 14 operaciones. Las concentraciones de alcalinidad para cada batch fueron diferentes, en un rango desde 120 a $360 \mathrm{mg}$ $\mathrm{CaCO}_{3} / \mathrm{dm}^{3}$. En cada batch se mantuvieron concentraciones de oxígeno disuelto de $4,3 \mathrm{mg} / \mathrm{dm}^{3}$, como mínimo y, cuando la concentración de $\mathrm{NO}_{3}{ }^{-}$se mantuvo sin descensos significativos, se dio por terminado el batch correspondiente a cada alcalinidad. Se procedió entonces al cálculo de la eficiencia de nitrificación $\left(\mathrm{E}_{\text {nitrif, }} \%\right)$ con base en:

Donde:

$$
E_{\text {nitrif }}=\frac{38-c_{f}\left(\mathrm{NO}_{3}^{-}\right)}{38} \times 100
$$

${ }_{38} \mathrm{mg} / \mathrm{dm}^{3}=$ concentración inicial de anión nitrato inicial de cada proceso batch;

$c_{f}\left(\mathrm{NO}_{3}^{-}\right)=$Concentración final de anión nitrato, $\mathrm{mg} / \mathrm{dm}^{3}$.

\section{Resultados y Discusión}

En el Cuadro se muestran los resultados de los 14 procesos batch, los que se grafican más adelante.

Cuadro. Variación de la concentración de $\mathrm{NO}_{3}{ }^{-}$y de la eficiencia de nitrificación en función de la alcalinidad.

\begin{tabular}{|c|c|c|}
\hline Alcalinidad como c $\left(\mathrm{CaCO}_{3}\right), \mathrm{mg} / \mathrm{dm}^{3}$ & Eficiencia en Nitrificación, \% & $\begin{array}{c}\mathrm{c}\left(\mathrm{NO}_{3}{ }^{-}\right), \\
\mathrm{mg} / \mathrm{dm}^{3}\end{array}$ \\
\hline 120 & 17 & 5,2 \\
\hline 140 & 19 & 5,10 \\
\hline 160 & 22 & 5,30 \\
\hline 180 & 28 & 5,31 \\
\hline 200 & 48 & 5,32 \\
\hline 220 & 62 & 7,22 \\
\hline 240 & 73 & 10,26 \\
\hline 260 & 81 & 14,44 \\
\hline 280 & 86 & 19,76 \\
\hline
\end{tabular}




\begin{tabular}{|c|c|c|}
\hline 300 & 86 & 27,36 \\
\hline 320 & 86 & 29,69 \\
\hline 340 & 87 & 30,78 \\
\hline 360 & 86 & 31,54 \\
\hline
\end{tabular}

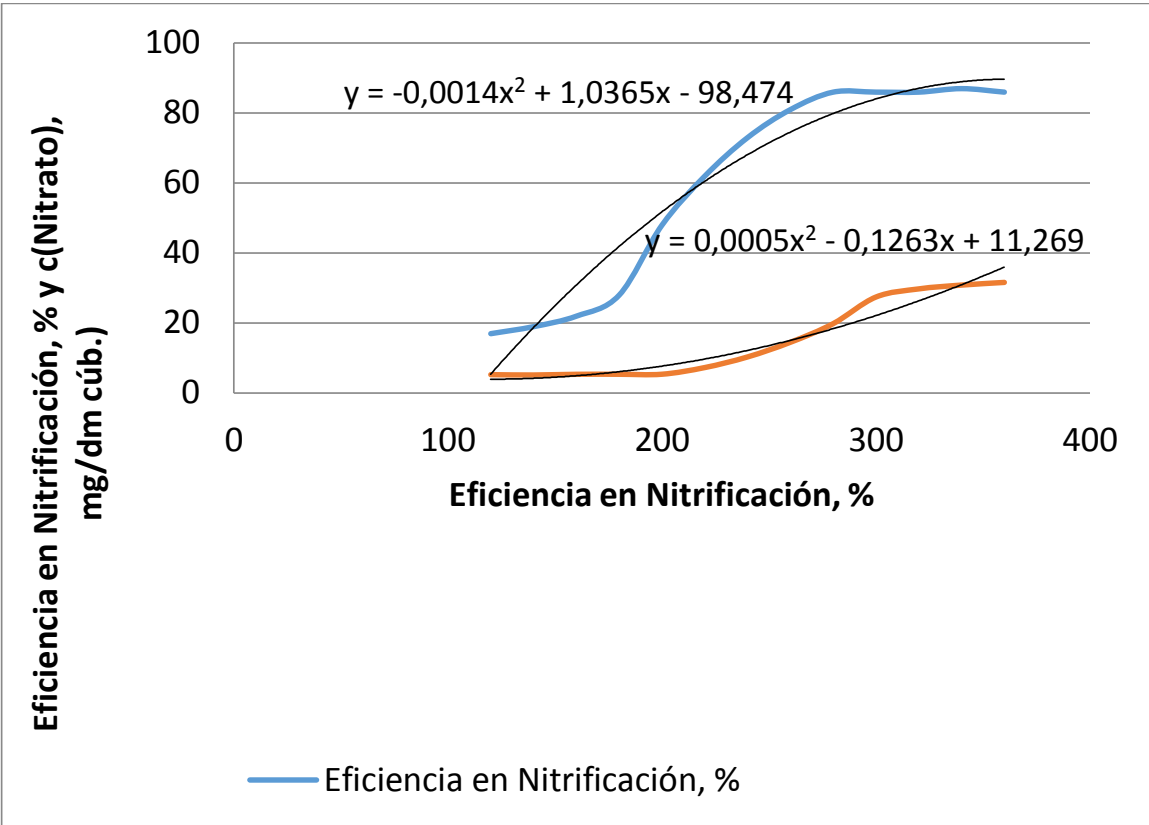

Gráfico. Variación de la concentración de $\mathrm{NO}_{3}{ }^{-}$y de la eficiencia de nitrificación en función de la alcalinidad

Se aprecia que al aumentar la alcalinidad también lo hace la eficiencia de nitrificación con la correspondiente disminución de la concentración de anión nitrato. Comenzando en el primer batch con una alcalinidad de $120 \mathrm{mg} / \mathrm{dm}^{3}$, se produjo un máximo de $86-87 \%$ de eficiencia de nitrificación para una alcalinidad de $260-360 \mathrm{mg} \mathrm{CaCO} / \mathrm{dm}^{3}$. En este rango se llega a valores mínimos de concentración del anión nitrato y a cifras máximas de eficiencias de nitrificación, correspondientemente.

También determinó un incremento de la concentración de anión nitrato en la medida en que aumenta la alcalinidad, partiendo desde 5,2 hasta 31,54 $\mathrm{mg} / \mathrm{dm}^{3}$, comportándose correspondientemente con la eficiencia de nitrificación.

Las curvas de ambos comportamientos se ajustan a las polinómicas, con coeficientes de correlación suficientemente altos $(0,97)$ :
a) $y=0,0005 x^{2}-0,1263 x+11,269 ; \quad$ para la concentración de nitrato.
b) $y=0,0014 x^{2}-1,0351 x-98,474 ; \quad$ para la eficiencia de nitrificación.


Este comportamiento es análogo, con sus lógicas diferencias, obtenido por Leiva et al. (2015) en sistemas similares a los lodos activados en reactores batch, completamente mezclados a escala de laboratorio. Es decir, que la alcalinidad del medio es un factor determinante en el avance del proceso de nitrificación. Sería recomendable hacer un estudio similar pero con la concentración de oxígeno disuelto como variable independiente del proceso de nitrificación.

\section{Conclusiones}

- $\quad$ Al incrementarse la alcalinidad en el reactor batch tipo laguna aireada a escala piloto, aumenta la concentración del anión $\mathrm{NO}_{3}{ }^{-}$, aumentando consecuentemente la eficiencia de nitrificación.

- Valores de alcalinidad en el rango 260 - $360 \mathrm{mg} \mathrm{CaCO} 3 / \mathrm{dm}^{3}$ causaron cifras mínimas de la concentración del anión $\mathrm{NO}_{3}{ }^{-}$, con los correspondientes máximos de la eficiencia de nitrificación., en los alrededores del 86\%.

- Los resultados satisfactorios sobre nitrificación se obtuvieron manteniendo una concentración mínima de oxígeno disuelto de $4,3 \mathrm{mg} / \mathrm{dm}^{3}$.

\section{References:}

1. Carrera, J. s/f. Eliminación biológica de nitrógeno en un efluente de alta carga. Universidad Autónoma de Barcelona, Barcelona, España.

2. Jarpa, M., et al. 2007. Determinación de la capacidad nitrificante de un sedimento marino proveniente de un centro de cultivo de salmones. INCI Vol. 32, No.10, Caracas, Venezuela.

3. APHA, AWWA, WPCF. 2000. Nitrogen ammonia phenate method. En: Standard methods for the examination of water and wastewater. Washington DC.

4. Leiva, A. 2015. Relación entre el tiempo de operación, la concentración de nitrógeno orgánico y la eficiencia nitrificadora en un sistema de lodos activados en batch. II Congreso internacional de Ingeniería Ambiental, UTE, Santo Domingo de los Tsáchilas, Ecuador.

5. Metcalf \& Eddy Inc. et al. 2003. Wastewater Engineering: Treatment and Reuse Ed. McGraw Hill Higher Education, 4th Edition. New York, USA.

6. Guía Ambiental. 2010. Disponible en http://www.guiaambiental.com.ar/conocimiento-calidad-deagua-lagunas-aireadas.html

7. Tchobanoglous, G. y Crites, R. 2000. Tratamiento de aguas residuales en pequeñas poblaciones. Ed. McGraw - Hill. New York, USA. 